\title{
FORMAÇÃO DE BIÓLOGOS: UMA COMPARAÇÃO ENTRE CURSOS PRESENCIAIS E À DISTÂNCIA
}

\author{
(TRAINING FOR BIOLOGISTS: A COMPARISON BETWEEN CLASSROOM COURSES AND \\ DISTANCE LEARNING)
}

\author{
Delano Moody Simões da Silva \\ Marcelo Ximenes Aguiar Bizerril \\ Ana Júlia Lemos Alves Pedreira \\ Universidade de Brasília, UnB (Brasil)
}

\section{RESUMO}

A presente pesquisa busca discutir as potencialidades e limitações dos modelos presencial e à distância de curso para a formação de professores de biologia no Brasil, a partir das percepções de professores e estudantes de ambas modalidades. Os resultados encontrados permitem definir alguns indicadores para a discussão sobre formação de biólogos. A percepção de alunos e professores de cursos presenciais sobre a EaD não reflete a realidade dos cursos, mas indica pontos que merecem uma reflexão para melhorar a qualidade dos egressos. Apesar das preocupações apresentadas pelos alunos a distância a maioria acredita numa boa formação nessa modalidade. A discussão a respeito das ferramentas de EaD na formação na graduação pode proporcionar uma maior reflexão sobre os métodos de ensino presencial nas universidades, sugerindo revisões em ambos modelos com possíveis contribuições do modelo a distância para o curso presencial e vice-versa.

Palavras-chave: formação inicial, educação a distância, formação de professores, ensino presencial

\begin{abstract}
The present study aims to evaluate the potential and limitations of the model classrooms and distance learning courses used for the training of biology teachers in Brazil, through a survey of the perceptions of teachers and students of both modalities. Our results allow us to identify some key issues relevant to a discussion of the training of biologists in Brazil. The perception of students and teachers in courses in the distance education program does not reflect the reality of the courses, but does indicate points that deserve consideration in order to improve the quality of graduates. Despite the concerns raised by the distance students most believe a good education is possible in this modality. The discussion of the tools of distance education in undergraduate education can provide material for further reflection on the methods of classroom teaching in universities, and can help us suggest revisions in both models with possible contributions from the distance model to the classroom course and vice versa.
\end{abstract}

Keywords: initial training, distance education, teacher training, classroom teaching. 
Temas como cidadania, participação, complexidade e interdisciplinaridade têm sido fortemente explorados na atualidade, momento no qual as sociedades humanas se ressentem da falta de paz, justiça social e sustentabilidade ambiental.

Diante desse quadro, o papel da educação surge inevitavelmente como protagonista das mudanças sociais, no entanto, fica o questionamento se os cursos de formação profissional de fato atendem a essas demandas. Para além dos conteúdos, os cursos de graduação estariam contribuindo para a formação desse cidadão do século XXI, apto a enfrentar os diversos problemas complexos e interdisciplinares que se apresentam?

Particularmente no que diz respeito a formação de professores tem-se conhecimento que a formação inicial é apenas um componente de uma estratégia mais ampla de profissionalização do professor, indispensável para implementar uma política de melhoria da educação básica (De Mello, 2000). Em geral, os cursos de licenciatura em Ciências Biológicas possuem maior parte de sua grade curricular voltada para conhecimentos específicos da área, reservando uma parte menor, algo em torno de 10\%, aos conhecimentos específicos à área de docência, o que leva a crer que o foco dos cursos de Ciências Biológicas está associado a outros temas que não a formação dos professores (Gatti e Barreto, 2009).

A concretização das mudanças desejadas na sociedade depende de mudanças qualitativas profundas na educação, mas também do quantitativo de pessoas com acesso à educação. Historicamente, a Educação a Distância (EaD) foi instalada pelos próprios governos para cumprir a tarefa de atingir um número expressivo de pessoas, em um aspecto de custos e benefícios mais satisfatório que as modalidades presenciais (Preti, 1998).

No Brasil, fala-se em EaD desde o início do século 20, com a criação da Rádio Sociedade do Rio de Janeiro (Saraiva, 1996; Farias, 1998). Mas foi a partir de década de 60 que a EAD intensificou-se a partir de programas como o MEB (1956), o projeto Minerva (1970), o Logos (1977), o Telecurso $2^{\circ}$ grau (1978), e o Mobral (1979). Mais recentemente, destacaram-se os programas "Um salto para o futuro" (1991), Telecurso 2000 (1995), e TV Escola (1996) (Neves, 1996; Preti 1998). Contudo, no Brasil ainda é muito incipiente a atuação da educação a distância no ensino de graduação. Um grande impulso a realização de cursos dessa natureza no Brasil foi dado com os programas do Ministério da Educação (MEC) Pró-licenciatura e Universidade Aberta do Brasil (UAB), a partir de 2005. Vale considerar que esses programas foram vistos, em um primeiro momento, com certo ceticismo pela comunidade 
acadêmica. O Decreto $\mathrm{n}^{0}$ 5.622, de 19 de dezembro de 2005 (Brasil,2005), que confere novo ordenamento legal para EAD no Brasil, define-a em seu artigo $1^{\circ}$ como "modalidade educacional na qual a mediação didático-pedagógica nos processos de ensino-aprendizagem ocorre com a utilização de meios e tecnologias de informação e comunicação, com estudantes e professores desenvolvendo atividades educativas em lugares ou tempos diversos" (Brasil, 2005).

O censo da Educação Superior de 2008 indicou crescimento no número de cursos a distância que chegou a 647, o que indica um crescimento de 96,9\% em relação ao ano de 2007. As matrículas no ensino a distância representaram 14,3\% do total de matrículas no ensino superior em 2008. Esse crescimento está associado ao aumento no acesso às tecnologias da informação e à facilidade de estudo que os cursos em EaD a princípio proporcionam aos estudantes (INEP, 2009).

Em 2008, a atitude do Conselho Federal de Biologia em não reconhecer licenciados em biologia de cursos a distância como biólogos gerou grande discussão sobre a capacidade de formação a distância no nível de graduação. Esse debate se estendeu até fevereiro de 2010, quando a Justiça Federal derrubou, por meio de liminar, a decisão do Conselho Federal de Biologia, por entender que é função do MEC reconhecer e fiscalizar a qualidade dos cursos superiores e, por essa razão, não deve haver diferenciação de diplomas pela modalidade de ensino (Madelli, 2010). O Decreto $n^{0} 5622$ de 19 de dezembro de 2005 determina no seu artigo $3^{0} \S 2^{\underline{0}}$ que: "os cursos e programas a distância poderão aceitar transferência e aproveitar estudos realizados pelos estudantes em cursos e programas presenciais, da mesma forma que as certificações totais ou parciais obtidas nos cursos e programas a distância poderão ser aceitas em outros cursos e programas a distância e em cursos e programas presenciais, conforme a legislação em vigor" (Brasil, 2005). Apesar do decreto, as críticas e resistências se propagam no meio acadêmico e na sociedade em meio ao grande desconhecimento do que seja a $\mathrm{EaD}$, suas metodologias e potencialidades, gerando uma clara necessidade de análise mais aprofundada sobre a percepção do brasileiro a respeito dos cursos a distância.

A última Conferência Nacional de Educação (CONAE, 2010) apresentou a seguinte orientação em seu texto final: "a formação inicial deverá se dar de forma presencial, inclusive aquelas destinadas aos/à professores/as leigos/as que atuam nos anos finais do ensino fundamental e no ensino médio, como aos/às professores/ as de educação infantil e anos iniciais do fundamental em exercício, possuidores/as de formação em nível médio. Assim, a formação inicial pode, de forma excepcional, ocorrer na modalidade de EaD para os/as profissionais da educação em exercício, 
onde não existam cursos presenciais, cuja oferta deve ser desenvolvida sob rígida regulamentação, acompanhamento e avaliação" (CONAE, 2010).

O resultado do Exame Nacional de Desempenho de Estudantes no ano de 2005 (ENADE), avaliou o desempenho dos alunos de ensino presencial e a distância, apontando que em 7 dos 13 cursos avaliados os alunos de EaD tiveram melhor desempenho do que os alunos presenciais. Em 2007 foi realizada uma nova pesquisa pelo Instituo Nacional de Estudos e Pesquisas Educacionais (INEP) que apontou que alunos de ensino presencial obtiveram as mesmas notas que os alunos de EaD no ENADE. Esse estudo analisou alunos com perfis semelhantes de idade, renda e estado civil (Folha de São Paulo, 2007).

A presente pesquisa buscou verificar a compreensão que os estudantes, nas modalidades presencial e à distância, apresentam em relação à formação que recebem em seus cursos e, para ambos casos, a avaliação que fazem da EaD como modalidade para formação de professores de biologia. Essas mesmas indagações foram feitas a professores universitários com diferentes graus de experiência com a EaD. A partir das percepções de estudantes e professores, buscou-se discutir potencialidades e limitações da EaD como modalidade de formação de professores de biologia.

\section{METODOLOGIA}

Dado o objetivo de indicar potenciais e limitações da EaD a partir das percepções de professores e estudantes quanto aos processos de formação de professores de biologia, foi feita opção por uma pesquisa de caráter qualitativo (Bogdan \& Biklen, 1994), com a escolha de um universo reduzido de sujeitos entrevistados e duas turmas de estudantes. Os questionários aplicados aos estudantes apresentaram quatro questões abertas a respeito dos pontos fortes e fracos do curso, das capacidades que destacam na formação profissional e da opinião sobre a modalidade EaD para formação de professores. O roteiro das entrevistas estruturadas com os professores considerou quatro aspectos: (1) o perfil desejado do biólogo; (2) uma análise do curso em que foi formado; (3) uma análise do curso que atua como professor; (4) uma análise sobre a modalidade EaD como opção para a formação de professores de biologia.

Foram entrevistados seis professores com experiência e atuação na formação de biólogos em diferentes instituições, e com diferentes graus de experiência com ensino na modalidade a distância. As entrevistas foram individuais, gravadas e posteriormente as respostas foram transcritas e analisadas. O agrupamento das 
respostas foi feito em categorias criadas a posteriori, no decorrer da análise. A percepção dos estudantes foi analisada por meio de um questionário aplicado a 24 estudantes do terceiro semestre de um curso presencial de biologia (licenciatura e bacharelado), e a 107 estudantes do terceiro semestre em curso de licenciatura de biologia a distância, ambos em universidades federais brasileiras. Para a análise foram considerados todos os estudantes matriculados no terceiro semestre de ambos os cursos. No decorrer deste estudo os alunos do curso presencial serão tratados como "alunos presenciais" e os alunos do curso a distância como "alunos a distância".

O curso presencial é representativo dos melhores cursos presenciais na área de biologia no país, seguindo o modelo presencial tradicional, ministrado em disciplinas de duas a seis horas semanais, com aulas expositivas e de laboratório e campo, totalizando quatro anos para integralização. O curso é constituído por um Ciclo Básico de 1875 horas, seguido de um Ciclo Profissional de 855 horas para a licenciatura ou 1155 para o bacharelado.

O curso à distância analisado tinha duração de quatro anos, com característica predominantemente a distância, contando também com atividades presenciais quinzenais. Os conteúdos eram apresentados aos estudantes predominantemente por meio de oito módulos semestrais com tratamento interdisciplinar organizado em grandes temas da biologia tais como energia, reprodução, desenvolvimento, aliados a temas da pedagogia e da atualidade. A mediação era feita por meio de um tutor que atendia os estudantes via e-mail, telefone, plataforma Moodle e plantões no pólo e por um tutor presencial que atendia os estudantes nos pólos nos dias de atividades presenciais onde ocorriam avaliações e aulas de laboratório. O curso era constituído por 3000 horas.

\section{RESULTADOS}

\section{Entrevistas com professores}

Todos os seis professores entrevistados se formaram em biologia em universidades públicas. A atuação atual dos entrevistados na formação de biólogos variou entre cursos de biologia em Universidades Federais e em Faculdades privadas.

A experiência dos professores em EaD também variou, sendo dois diretamente envolvidos em cursos de licenciatura em biologia a distância, dois com experiência pontual em um curso de especialização em ensino de ciências para professores e dois 
sem experiência anterior em EaD. Nenhum dos professores teve a experiência como aluno em cursos a distância.

A atuação profissional também variou, incluindo atuação técnica em consultoria e administração, mas sendo comum a todos, a atuação em pesquisa e em ensino de biologia. O tempo de exercício profissional variou entre 13 e 29 anos.

\section{O perfil ideal de biólogo:}

As principais capacidades de um recém-formado indicadas por todos os entrevistados foram: (a) autonomia na busca de conhecimentos, buscando e qualificando a informação; (b) organização da informação e comunicação na forma escrita e oral; (c) motivação para fazer perguntas, do ponto de vista científico; (d) conhecimento teórico sólido de conceitos e processos-chave das ciências biológicas; (e) aplicação adequada do conhecimento obtido na análise de problemas, interligando as diversas áreas da biologia.

A percepção sobre os cursos presenciais:

Os entrevistados apresentaram mais precisão em apontar limitações para a formação de biólogos nos cursos em que trabalham atualmente do que pontos positivos. Frequentemente os entrevistados utilizaram os cursos que os formaram como base para comparações com as experiências atuais, agora como formadores. Como pontos positivos dos cursos atuais, todos destacaram a boa base de conteúdo. Alguns se remeteram ao fato de ser discutida a interdisciplinaridade na ciência, e outros afirmaram atender bem à formação de professores, pois o curso apresentaria uma experiência mais voltada ao universo escolar. Esse último caso foi mais freqüente nos professores de faculdades privadas.

As limitações apontadas nos cursos atuais foram diversificadas, ligadas a aspectos pedagógicos, mas também estruturais e de atitude de estudantes e professores (quadro 1). 
- Interação professor-aluno

o Há uma ausência de espaços espontâneos de interação entre professores e estudantes, que restringe-se em muitos casos ao momento da aula.

- Comportamento dos estudantes

o Apesar de publicarem mais, aparentemente alunos sabem mais técnicas, mas refletem e perguntam menos, pois se tornaram mais pragmáticos e menos curiosos.

o Os estudantes têm dificuldades de perguntar e se expressar.

o Os estudantes estudam pouca teoria da evolução, especialmente em cursos como botânica e biologia celular.

o Os estudantes em geral não lêem em inglês.

o Em cursos noturnos há menos tempo e interesse dos alunos no estudo.

- Aspectos estruturais do curso

o Disciplinas complexas, como é o caso de ecologia, quando dadas no início do curso são pouco aproveitadas.

o Há menos tempo para formar os alunos no caso de cursos de licenciatura em 3 anos.

o Houve redução de atividades extra-curriculares.

- A busca da informação e comunicação da mesma se dá apenas na parte final do curso por meio dos trabalhos finais de conclusão de curso.

- Aspectos pedagógicos

o Há falta de diálogo entre professores que dão a parte de ensino e os que dão os conteúdos específicos.

o O curso não favorece a integração entre os conhecimentos, pois o processo está muito centrado no professor.

Quadro 1. Limitações à formação de biólogos nos cursos presenciais atuais, segundo os entrevistados

\section{A percepção sobre os cursos a distância:}

Os entrevistados se colocaram na posição de observadores da capacidade de um curso a distância formar adequadamente biólogos. Foram muito claros em apontar que licenciados em biologia seriam mais facilmente formados por essa modalidade 
que bacharéis. Enxergam pontos positivos na modalidade EaD, no entanto têm preocupação quanto a possibilidade de serem desenvolvidas, nessa modalidade, algumas atividades tradicionais na formação presencial de biólogos. Alguns deixaram claro que consideram que a EaD seja eficaz para temas mais pontuais, como cursos de extensão e especialização e treinamentos profissionais, do que para cursos formativos, como é o caso das graduações.

É interessante notar que as limitações apontadas nessa modalidade na formação de biólogos variou entre os professores de acordo com seu nível de contato com a EaD (quadros 2 e 3) sendo que os professores com experiências recentes em EaD apontaram limitações mais específicas, voltadas ao dia-a-dia do curso à distância ao passo que os demais professores se ativeram a listar preocupações decorrentes da redução do contato presencial. Professores com contato com EaD também foram mais precisos em apontar pontos positivos dessa modalidade de ensino.

\section{Limitações}

- Interação professor-aluno

o O reduzido contato com o professor nas discussões e acompanhamento das atividades.

o A dificuldade de se perceber individualidades em turmas grandes a distância.

- Comportamento dos estudantes

o A ausência de disciplina para estudar a distância, já que esses estudantes não foram treinados nas fases anteriores de formação.

- Aspectos estruturais do curso

o Os espaços de discussão a distância - como os fóruns virtuais - podem ser insuficientes para possibilitar o debate e a afetividade que são a base para o desenvolvimento da criatividade.

- A limitação de realização de atividades práticas e estágios, de pesquisa e docentes;

o A limitação de possibilidades para apresentação oral de trabalhos. 
- Aspectos pedagógicos

o O ensino de ciências precisa ser lúdico e isso só seria possível com orientação.

o O ensino precisa acompanhar as peculiaridades do país, portanto não pode ser genérico.

o É preciso que todos estejam acompanhando/aprendendo ao mesmo tempo e isso não é possível ser feito a distância.

- Outros

o Falta de credibilidade na academia e na sociedade devido ao medo do que é novo.

o O entendimento de que graduação é curso de formação, necessitando de orientação presencial.

\section{Pontos positivos}

- Oportunidade de acesso ao nível superior por parte do público periférico pela localização das suas cidades ou por reduzida disponibilidade de tempo para estudo.

Quadro 2. Limitações e aspectos positivos para a formação do biólogo em cursos à distância segundo professores com pouco envolvimento com $\mathrm{EaD}$ 


\section{Limitações}

- Interação professor-aluno

o Dificuldade de capacitação do tutor em diversas áreas do conhecimento.

- Comportamento dos estudantes

o Dificuldades no acompanhamento e no estabelecimento de rotina de estudo dos alunos.

- Aspectos estruturais do curso

o A distância entre pólos dificulta as possibilidades de realizar estágios.

- Aspectos pedagógicos

o Alguns temas são de difícil compreensão a distância, como a química, por exemplo.

\section{Pontos positivos}

- A possibilidade de desenvolvimento da autonomia do estudante.

- A possibilidade de abordagem mais interdisciplinar em um mesmo material educativo.

- O maior envolvimento da comunidade local no aprendizado.

- O atendimento a grande demanda por formação de professores de ciências.

- O desenvolvimento de certas habilidades rapidamente como é o caso do uso das Tecnologias de Informação e Comunicação (TICs).

Quadro 3. Limitações e aspectos positivos para a formação do biólogo em cursos à distância segundo professores com experiências recentes com $\mathrm{EaD}$

Uma das professoras entrevistadas deixou claro que a boa formação e a capacidade de aprender depende de cada indivíduo, e por isso, a EaD pode ser perfeitamente bem sucedida em formar pessoas em qualquer área que seja. 


\section{Questionários com alunos}

A maioria dos alunos do curso a distância (60\%) não cursou um curso superior, sendo que o restante (40\%) cursou um curso superior completo ou deu início a algum. No caso dos alunos presenciais, esse é o primeiro curso superior que todos estão cursando.

Quando perguntamos aos alunos se eles já tiveram alguma experiência com o ensino à distância, apenas 21 alunos do curso a distância (20\%) já tinham tido contato anterior com esta modalidade. Os alunos presenciais que responderam ao questionário não tiveram nenhum contato com o ensino à distância.

Ao analisarmos os pontos positivos indicados pelos alunos a distância, constamos que a maioria indica a flexibilidade de horário e a autonomia que o curso proporciona como pontos mais importantes, sendo que alguns alunos colocam o último como determinante para a escolha do curso. Fatores como material didático, qualidade do curso e acesso ao conhecimento são pouco freqüentes nas respostas dos alunos a distância (tabela 1).

\begin{tabular}{lcc}
\hline PONTOS & FREQUÊNCIA & \% \\
\hline Flexibilidade & 39 & 23,6 \\
Autonomia & 32 & 19,4 \\
Tutores & 19 & 11,5 \\
Responsabilidade & 11 & 6,7 \\
Material didático & 9 & 5,4 \\
Aulas presenciais & 8 & 4,8 \\
Acesso ao conhecimento & 7 & 4,2 \\
Estrutura pedagógica & 4 & 2,4 \\
Qualidade do curso & 4 & 2,4 \\
Outros ${ }^{1}$ & 32 & 19,4 \\
\hline TOTAL & $\mathbf{1 6 5}$ & $\mathbf{1 0 0 , 0}$ \\
\hline
\end{tabular}

1 Outros: Nessa categoria estão pontos positivos que foram pouco freqüentes, como: Plataforma, valorização do estudo, e etc.

Tabela 1. Pontos positivos indicados pelos alunos de um curso a distância 
Quando a mesma questão é colocada para os alunos presenciais os pontos positivos mais citados para o seu curso estão relacionados à qualidade de seus professores, a abrangência do curso e a estrutura que a instituição oferece, além do contato com a pesquisa que o mesmo proporciona. Apenas 12,5\% dos alunos citaram as aulas práticas como um ponto positivo do seu curso (tabela 2).

\begin{tabular}{lcc}
\hline PONTOS & FREQUÊNCIA & \% \\
\hline Professores & 11 & 27,5 \\
Abrangência & 7 & 17,5 \\
Estrutura & 6 & 15,0 \\
Acesso aos professores & 5 & 12,5 \\
Pesquisa & 5 & 12,5 \\
Aulas práticas & 5 & 12,5 \\
Disciplinas & 1 & 2,5 \\
\hline TOTAL & $\mathbf{4 0}$ & $\mathbf{1 0 0 , 0}$ \\
\hline
\end{tabular}

Tabela 2. Pontos positivos indicados pelos alunos de um curso presencial

Quanto aos aspectos negativos de cada curso, os alunos a distância citaram como preocupantes o atendimento pedagógico (tutores e monitores), o material didático (módulos), e a falta de aulas, tanto expositivas quanto práticas. No caso do atendimento pedagógico, os alunos questionam que o atendimento de tutores e monitores não é suficiente para esclarecer suas dúvidas e que eles necessitariam de mais apoio por parte dos mesmos. Quanto à falta de aulas expositivas e práticas, a maioria dos alunos ainda tem dificuldade em aceitar o formato de um curso a distância onde se tem poucos encontros presenciais. Um fato que reforça essa percepção é que alguns alunos freqüentam o pólo regularmente não só para tirar dúvidas, mas sim para estudarem sob a supervisão do tutor presencial. Alguns alunos questionaram a falta de material de apoio ou de recursos didáticos como, por exemplo, mais material de leitura, apresentações de slides ou mesmo vídeo-aulas para que pudessem complementar seus estudos (tabela 3). 


\begin{tabular}{lcc}
\hline PONTOS & FREQUÊNCIA & $\%$ \\
\hline Tutores/monitores & 27 & 17,6 \\
Material didático & 22 & 14,4 \\
Falta de aulas presenciais & 21 & 13,7 \\
Falta de material de apoio & 11 & 7,2 \\
Estrutura do pólo & 9 & 5,9 \\
Atendimento & 6 & 3,9 \\
Orientação de estudo & 6 & 3,9 \\
Conteúdos difíceis/superficiais & 6 & 3,9 \\
Organização & 5 & 3,3 \\
Avaliação & 5 & 3,3 \\
Falta de um professor presencial & 4 & 2,6 \\
Contato com os demais alunos $_{\text {Outros }}{ }^{1}$ & 4 & 2,6 \\
TOTAL & 27 & $\mathbf{1 7}, 6$ \\
\hline
\end{tabular}

${ }^{1}$ Outros: Nessa categoria foram agrupados pontos negativos que foram citados menos de três vezes pelos alunos, como: Insegurança dos alunos, falta de seminários e outros. Tabela 3. Pontos negativos indicados pelos alunos de um curso a distância

Para os alunos presenciais as críticas se concentraram na atuação dos professores, e pouco se falou quanto à estrutura do curso ou da própria instituição. A falta de comprometimento com a atividade de docência por parte dos professores foi o ponto mais citado pelos alunos presenciais, seguido de uma carga horária insuficiente para muitas disciplinas. Segundo esses alunos, em muitas situações o conteúdo trabalhado pelos professores necessitaria de uma maior carga horária (tabela 4).

\begin{tabular}{lcc}
\hline PONTOS & FREQUÊNCIA & \% \\
\hline Comprometimento dos professores & 9 & 37,5 \\
Carga horária insuficiente para algumas disciplinas $^{1}$ & 6 & 25,0 \\
Outros $^{1}$ & 9 & 37,5 \\
\hline TOTAL & $\mathbf{2 4}$ & $\mathbf{1 0 0 , 0}$ \\
\hline
\end{tabular}

${ }^{1}$ Outros: Nessa categoria foram agrupados os pontos negativos citados menos de três vezes, como: Falta de recursos para saídas de campo, falta de aprofundamento de conteúdos e outros. Tabela 4. Pontos negativos indicados pelos alunos de um curso presencial 
A maioria dos alunos a distância $(95,9 \%)$ acredita que é possível formar biólogos em cursos na modalidade a distância, porém afirmam que isso depende muito do empenho do próprio aluno e de ajustes na estrutura do próprio curso. Chama a atenção que 4,1\% dos alunos que responderam ao questionário acham que não é possível formar um biólogo nessa modalidade ou tem dúvidas quanto a isso. Dentre os alunos que acreditam que seja possível a formação de biólogo nessa modalidade, $33,3 \%$ acredita que seja possível formar um professor, mas não um cientista.

No caso dos alunos presencias a maioria $(70,8 \%)$ acha que não é possível formar biólogos em cursos a distância, pois esse é um curso com muitas atividades práticas e que isso seria inviável nessa modalidade. Dentre os alunos que acreditam que é possível formar um biólogo nesse formato, o empenho pessoal ou a existência de aulas práticas foram colocadas como condicionantes para essa formação.

Quando perguntamos aos dois grupos de alunos quais as capacidades que seus cursos lhes proporcionariam, obtivemos uma dicotomia interessante. Os alunos a distância citaram a autonomia, os conhecimentos relacionados a biologia, a responsabilidade, a capacidade de buscar conhecimento e a independência como as principais capacidades a serem desenvolvidas no seu curso. Já os alunos presenciais citaram os conhecimentos relacionados a atividades do biólogo como a principal capacidade a ser desenvolvida no seu curso, seguido de experiência com pesquisa e a capacidade crítica. Capacidades como autonomia e independência, importantes em qualquer formação, foram citadas apenas por três alunos, ou seja, os alunos a distancia vêem a possibilidade de desenvolver capacidades mais amplas, importantes em qualquer profissão, mas fundamentais na carreira docente. Enquanto os alunos presenciais demonstraram uma maior preocupação com capacidades que estão mais relacionadas à área de pesquisa.

\section{DISCUSSÃO}

O perfil do biólogo idealizado pelos professores sugere que durante a sua formação, o futuro profissional deveria aprender conteúdos específicos da área de conhecimento e também desenvolver habilidades que não são restritas a biologia, como autonomia, capacidade de expressão oral e escrita, dentre outras. Porém para que o estudante possa desenvolver essas capacidades é de fundamental importância que eles vivenciem situações que possibilitem o desenvolvimento das mesmas (Thomaz, 2000; Gatti, 2010). A aprendizagem de determinados conteúdos como atitudes e procedimentos requerem estratégias de ensino diferenciadas com uma explicita relação entre a teoria e a prática (Pozo e Crespo, 2009; Gatti, 2010). 
A preocupação com conteúdo está presente nas indicações, e ela é legítima, uma vez que estamos tratando da formação inicial de um profissional e essa etapa tem que possibilitar que o mesmo atue no mercado de trabalho ou dê continuidade na sua formação em cursos de pós-graduação. Os currículos de cursos de Biologia privilegiam esse componente, sendo que na maioria dos cursos $65 \%$ das disciplinas são de conhecimento específico da área (Gatti, 2008).

A percepção dos professores de que licenciados seriam mais facilmente formados na modalidade a distância que bacharéis exemplifica uma visão comum entre os formadores e os profissionais da área de biologia e de outras ciências: a de que a formação de professores é uma atividade de categoria inferior e quem se dedica a ela é pouco valorizado (Gatti, 2008). Porque professores seriam mais facilmente formados que bacharéis?

O ensino das ciências é mais eficiente e interessante quando os alunos, nos mais diversos níveis de escolaridade, interagem com os objetos de estudo através de atividades práticas ou de caráter investigativo (Thomaz, 2000; Pozo e Crespo, 2009). Sendo assim, o desafio em formar um professor de biologia se torna tão ou mais complexo que formar um bacharel na modalidade à distância.

As limitações apontadas pelos professores são reflexo do pouco conhecimento sobre a modalidade a distância ou por problemas ocorridos em experiências anteriores com essa modalidade. Essas limitações apontadas pelos professores que tiveram pouco contato com EaD poderiam, quase na sua totalidade, serem atribuídas também a um curso presencial, pois não estão relacionadas a modalidade, mas sim a aspectos formativos mais amplos, como por exemplo, as limitações na formação pedagógica dos professores no ensino superior, ou a maior valorização acadêmica dada à pesquisa e pós-graduação em relação ao ensino de graduação. Da mesma forma, os pontos positivos indicados pelos professores poderiam ser transpostos para um curso presencial, pois independem da modalidade. A única exceção seria a abrangência que a EaD possibilita, sendo essa um das principais justificativas para o seu desenvolvimento.

A percepção que os alunos a distância e presencias apresentam sobre seus cursos reflete a concepção de formação superior que cada grupo possui. Os alunos de ensino a distância vêem a flexibilidade de horário e a autonomia para estudarem como os pontos mais positivos do seu curso, ou seja, eles se colocam em primeiro plano no seu processo formativo e isso é corroborado posteriormente quando afirmam que é possível formar um biólogo nessa modalidade e que isso só dependerá 
deles. Essas características do ensino a distância também são identificadas por Sá (2008) ao indicar propriedades específicas dessa modalidade de ensino, tais como: o estudo individualizado e independente, o que leva o aluno a uma maior autonomia na aprendizagem, a relação de espaço e tempo distintos entre professor e aluno, além de apontar outros aspectos tais como a comunicação bidirecional, o trabalho cooperativo, e o processo de ensino-aprendizagem mediatizado entre os sujeitos que participam da ação pedagógica. Vale ainda ressaltar ser essa flexibilidade no tempo fator determinante para que o aluno faça o curso, uma vez que na maioria dos casos, os alunos do curso a distância são pessoas que trabalham em algum turno do dia ou que não podem se ausentar de casa para estudar presencialmente.

Por outro lado, os alunos presenciais indicam os professores e a abrangência de seu curso como pontos positivos, colocando professores e conteúdos no primeiro plano de seu processo formativo, ou seja, um ensino centrado no professor com uma valorização de aquisição de conteúdos. Novamente, a aquisição de conteúdos não é uma limitação, mas ela deve ser considerada de forma contextualizada e abrangendo toda a natureza do conhecimento. Vale ressaltar que os alunos presenciais que participaram desse trabalho nunca tiveram contato com o ensino a distância, o que pode, por desconhecimento, levá-los a um preconceito em relação a esse tipo de modalidade de ensino.

Os principais pontos negativos apontados pelos alunos a distância estão relacionados aos aspectos que interferem na mediação do seu processo de aprendizagem, como apoio pedagógico e material para estudo. A falta de aulas presenciais também é indicada com um ponto relevante e merece uma reflexão. Um curso de formação inicial na modalidade a distância em qualquer área necessita de momentos presenciais. Além de proporcionar a resolução de dúvidas sobre as atividades, também possibilita interação aluno-aluno e aluno-tutor/professor, as quais são fundamentais no processo de ensino-aprendizagem. Ainda que essa interação ocorra virtualmente, nos momentos presenciais os alunos interagem mais o que muitas vezes fortalece esse vínculo virtual. A maior interação entre os alunos pode proporcionar momentos de estudo coletivo, o que melhora significativamente o processo de aprendizagem desses alunos. As capacidades que os alunos irão desenvolver refletem o que foi discutido anteriormente. Os alunos a distância valorizam aspectos formativos diferentes dos alunos presenciais, sendo que o primeiro grupo ressalta atitudes e comportamentos que possibilitam uma ampliação da sua formação enquanto profissional enquanto os alunos presenciais se voltam mais a valorização do conhecimento em si. 
O objetivo desse trabalho não é contrapor as duas modalidades, mas sim fazer uma reflexão sobre o processo de formação em ambas. Ambos cursos possibilitam o desenvolvimento de várias capacidades, sendo muitas em comum. Ocorre que nos dois casos deve-se avaliar as possibilidades de melhorar o processo dessa formação. Seria interessante que um aluno, ao optar por uma das modalidades de curso, pudesse ter em mente quais as diferentes capacidades que são desenvolvidas em cada uma delas.

Ambas modalidades possuem peculiaridades que as tornam diferentes entre si. É muito mais fácil as pessoas aceitarem o ensino presencial, uma vez que já o experimentaram em algum momento da vida. Já o ensino a distância, por se tratar de uma modalidade de ensino menos difundida, sofre ainda muitas críticas, muitas das quais se aplicam também ao ensino presencial.

Sá (2008) afirma que: "a EaD tem muito o que contribuir para a chamada educação presencial, assim como esta tem para com a $\mathrm{EaD}$, porém ambas têm suas naturezas e suas especificidades que devem ser observadas quando se fala em qualidade (formal e política) da educação".

\section{CONCLUSÕES}

Apesar de tratar-se de um estudo restrito a um universo reduzido de professores e estudantes, os resultados apresentados permitem definir alguns indicadores para a discussão sobre formação de biólogos. Aparentemente, há uma percepção tanto de estudantes quanto de professores de cursos presenciais que um curso a distância dispensa momentos presenciais e realização de estágios. Apesar disso não ser a verdade para os cursos a distância, é certo que se pode considerar os ajustes necessários para melhorar a qualidade do egresso, tendo como foco a ampliação de espaços informais de discussão sobre ciência, acesso a estágios e atividades práticas presenciais, como é o caso das exposições orais.

A percepção de estudantes e professores envolvidos com EaD fortalece a idéia de que a autonomia no estudo, e a consciência da importância dessa capacidade, são fortemente trabalhados nos cursos dessa modalidade. A possibilidade de integração dos conhecimentos da biologia também é um forte trunfo do material didático e da abordagem dada ao ensino. Ficaram registradas as preocupações com a parte operacional dos cursos a distância relacionados a capacitação dos tutores, acompanhamento dos estudantes e acesso a estágios técnicos de qualidade. 
Com a criação da Universidade Aberta do Brasil as perspectivas são de grande aumento na oferta de cursos de graduação a distância. A avaliação das experiências que estão em andamento é importante para a compreensão da receptividade dos cursos a distância pelos estudantes e pelas comunidades acadêmicas, como também para vislumbrar as possíveis dificuldades enfrentadas pelos cursos para atingir a excelência em formação superior.

A discussão a respeito das ferramentas de EaD na formação na graduação pode também ter efeito na maior reflexão sobre os métodos de ensino presencial nas universidades, sugerindo revisões em ambos modelos com possíveis contribuições do modelo a distância para o curso presencial, e vice-versa.

\section{REFERÊNCIAS BIBLIOGRÁFICAS}

Bogdan, R. C.; Biklen, S. K. (1994). Investigação qualitativa em educação: uma introdução à teoria e aos métodos. Portugal: Porto Editora.

Brasil (1998). Decreto $\mathrm{n}^{0}$ 2.561, de 27 de abril de 1998. [em linea] Disponível em: http://portal.mec.gov.br/seed/ arquivos/pdf/tvescola/leis/D2561.pdf (consulta 2011, 17 de novembro).

Brasil (2005). Decreto n. 5622 de 19 de dezembrode 2005. [emlinea] Disponível em http://www010.dataprev.gov.br/ sislex/paginas/23/2005/5622.htm (consulta 2011, 17 de novembro).

CONAE (2010). Conferência Nacional de Educação. Ministério da Educação, 2010. Documento Final. [em linea] Disponível em: http://conae.mec. gov.br/images/stories/pdf/pdf/ documetos/documento final sl.pdf (consulta 2011, 15 de outubro).

De Mello, G. N. (2000). Formação inicial de professores para a educação básica: uma (re)visão radical. São Paulo em perspectiva, 14 (1), (98-110).

Farias, M. F. (1998). Momentos da educação a distância no Brasil. Educação em debate 20 (35), (89-98).
Folha de São Paulo (2007).Aluno a distância vai melhor no Enade. Folha de São Paulo, São Paulo. [em linea] Disponível em: http://www1.folha.uol.com.br/ folha/educacao/ult305u327081.shtml (consulta 2011, 17 de novembro).

Gatti, B. A.; Barreto, E. S. (2009). Professores do Brasil: impasses $e$ desafios. Brasília: UNESCO.

Gatti, B. A.; outros. (2008). Formação de professores para o ensino fundamental: instituições formadoras e seus currículos: relatório de pesquisa. São Paulo: Fundação Carlos Chagas; Fundação Victor Civita, 2v.

Gatti, B. A. (2010). Formação de professores no Brasil: Características e Problemas. Educação e Sociedade, Campinas, 31 (113), (1355-1379).

INEP - Instituto Nacional de Estudos e Pesquisas Educacionais (2009). Divulgando o censo da Educação Superior 2008. [em linea] Disponível em: http://www.inep.gov.br/imprensa/ noticias/censo/superior/newsog 05. htm (consulta 2010, 1 de dezembro).

Mandelli, M. (2010). Curso a distância de Biologia tem validade para registro profissional. O Estado de São Paulo, 
São Paulo [em linea]. Disponível em: http://www.estadao.com.br/noticias/ impresso,curso-a-distancia-debiologia-tem-validade-para-registroprofissional,508886,0.htm (consulta 2011, 17 de novembro).

Neves, C. M. C. (1996). O desafio contemporâneo da educação a distância. Em aberto 16 (70), (34-41).

Pozo, J. I.; Crespo, M. A. G. (2009). A aprendizagem e o ensino de ciências: do conhecimento cotidiano ao conhecimento científico. Porto Alegre: Artmed.

Preti, O. (1998). Educação a distância e globalização: desafios e tendências. R.bras.Est.pedag. 79 (191), (19-30).
Sá, R. A. (2008). Curso de graduação na área de formação de professores na modalidade de ead: a qualidade sob à ótica sistêmico-organizaciona. RIED. Revista Iberoamericana de Educación a Distancia, 11 (2) [em línea]. Disponível em: http://www.utpl.edu. ec/ried/images/pdfs/volumen11N2/ cursodegraduacao.pdf (consulta 2012, 10 de abril).

Saraiva, T. (1996). Educação a distância no Brasil: lições da história. Em aberto 16 (70), (17-27).

Thomaz, M. F. (2000). A Experimentação e a formação de professores de ciências: uma reflexão. Caderno Catarinense de Ensino de Física, 17 (3), (360-369).

\section{PERFIL PROFISSIONAL E ACADÊMICO DAS AUTORES}

Delano Moody Simões da Silva. Graduado em Ciências Biológicas com mestrado e doutorado em Ecologia pela Universidade de Brasília. Atuou em cursos de Licenciatura e de formação de professores. É professor adjunto da Universidade de Brasília desde de 2009. Atua principalmente nos seguintes temas: Ensino de Ciências, Ensino de Biologia e Formação de Professores.

E-mail:delanom@unb.br

Marcelo Ximenes Aguiar Bizerril. Graduado em Ciências Biológicas com mestrado e doutorado em Ecologia pela Universidade de Brasília. Trabalha com formação de educadores desde 1996 e é professor adjunto da Universidade de Brasília desde 2006. Atua principalmente nos seguintes temas: educação ambiental, ensino de ciências e biologia e comunicação comunitária.

E-mail: bizerril@unb.br

Ana Júlia Lemos Alves Pedreira. Graduada em Ciências Biológicas pela Universidade Federal de Viçosa e com mestrado em Ecologia pela Universidade de Brasília. Especialista em Educação a Distância (CEAD/UnB) atuou como consultora do Ministério da Educação em cursos de formação continuada de professores na 
modalidade a distância. Atua principalmente nos seguintes temas: Educação Ambiental, Formação de professores, Educação a Distância e Ensino de Biologia.

E-mail: anajuliapa@terra.com.br

DIRECCIÓN DE LOS AUTORES

Prof. Delano M. Simões da Silva

Faculdade UnB Planaltina

Universidade de Brasília

Área Universitária n. 1 - Vila Nossa

Senhora de Fátima

73.300-000 - Planaltina - DF - Brasil

Fecha de recepción del artículo: 22/11/11

Fecha de aceptación del artículo: 9/03/12

\section{Como citar este artículo:}

Simões da Silva, D. M.; Ximenes Aguiar Bizerril, M.; Lemos Alves Pedreira, A. J. (2012). Formação de biólogos: uma comparação entre cursos presenciais e à distância. RIED. Revista Iberoamericana de Educación a Distancia, volumen 15, $\mathrm{n}^{\mathrm{O}}$ 2, pp. 171-190. 